\title{
Dendritic cells: key players in human herpesvirus 8 infection and pathogenesis
}

\author{
Diana M. Campbell ${ }^{1}$, Giovanna Rappocciolo ${ }^{1}$, Frank J. Jenkins ${ }^{1,2}$ and Charles R. Rinaldo ${ }^{1,2}$ * \\ ' Department of Infectious Diseases and Microbiology, Graduate School of Public Health, University of Pittsburgh, Pittsburgh, PA, USA \\ ${ }^{2}$ Department of Pathology, School of Medicine, University of Pittsburgh, Pittsburgh, PA, USA
}

\section{Edited by:}

Michael McVoy, Virginia

Commonwealth University, USA

\section{Reviewed by:}

Michael McVoy, Virginia

Commonwealth University, USA

Alberto Faggioni, University of Rome

La Sapienza, Italy

\section{${ }^{*}$ Correspondence:}

Charles R. Rinaldo, Department of Infectious Diseases and Microbiology, Graduate School of Public Health, University of Pittsburgh, A419 Crabtree Hall, 130 DeSoto Street, Pittsburgh, PA 15261, USA e-mail: rinaldo@pitt.edu
Human herpesvirus 8 (HHV-8; Kaposi's sarcoma-associated herpesvirus) is an oncogenic gammaherpesvirus that primarily infects cells of the immune and vascular systems. HHV-8 interacts with and targets professional antigen presenting cells and influences their function. Infection alters the maturation, antigen presentation, and immune activation capabilities of certain dendritic cells (DC) despite non-robust lytic replication in these cells. DC sustains a low level of antiviral functionality during HHV-8 infection in vitro. This may explain the ability of healthy individuals to effectively control this virus without disease. Following an immune compromising event, such as organ transplantation or human immunodeficiency virus type 1 infection, a reduced cellular antiviral response against HHV-8 compounded with skewed DC cytokine production and antigen presentation likely contributes to the development of HHV-8 associated diseases, i.e., Kaposi's sarcoma and certain B cell lymphomas. In this review we focus on the role of DC in the establishment of HHV-8 primary and latent infection, the functional state of DC during HHV-8 infection, and the current understanding of the factors influencing virus-DC interactions in the context of HHV-8-associated disease.

Keywords: human herpesvirus 8 (HHV-8), herpesviruses, dendritic cells, Kaposi's sarcoma-associated herpesvirus (KSHV), Kaposi's sarcoma, primary effusion lymphoma, multicentric Castleman's disease, DC-SIGN

\section{BACKGROUND}

Human herpesvirus 8 (HHV-8) is one of eight herpesviruses known to infect and establish chronic latency in humans. Also known as Kaposi's sarcoma-associated herpesvirus (KSHV), HHV-8 was first identified as a gammaherpesvirus in 1994 in AIDS patients with Kaposi's sarcoma (KS; Chang et al., 1994). HHV-8 has since been recognized as the causal agent of all four distinct forms of KS: classic KS in elderly European and Mediterranean men, endemic KS in human immunodeficiency virus type 1 (HIV-1) negative African populations, iatrogenic KS in immunosuppressed patients post-transplantation, and AIDS-KS in HIV-1 infected populations. It is also acknowledged as a common factor in the development of two B cell lymphomas, i.e., primary effusion lymphoma (PEL) and a subset of Castleman's disease cases known as multicentric Castleman's disease (MCD; Chang et al., 1994; Cesarman et al., 1995; Soulier et al., 1995; Nador et al., 1996; Cesarman and Knowles, 1999).

This double-stranded DNA virus targets several cell types for infection in vivo and in vitro where it either replicates or establishes latency. Of particular interest is that HHV- 8 targets so-called professional antigen presenting cells (APC) including monocytederived dendritic cells (MDDC; Rappocciolo etal., 2006a), B cells (Ambroziak et al., 1995; Rappocciolo et al., 2008; Myoung and Ganem, 2011) and monocytes (Blasig et al., 1997), as well as endothelial cells (Boshoff et al., 1995). Indeed, while HHV-8 infected and uninfected endothelial and spindle cells form neoplastic KS lesions (Boshoff et al., 1995), infected and uninfected B cells and monocytes are found proximal to KS lesions (Ambroziak et al., 1995; Blasig et al., 1997). The role of dendritic cells (DC) in antigen presentation and immune activation suggests these functions, or lack thereof, could be involved in the development of HHV-8 diseases associated with a compromised immune system.

Myeloid dendritic cells (mDC), including Langerhan cells (LC), skin dermal dendritic cells (DDC), submucosal dermal dendritic cells (SMDC), and MDDC, have essential roles in both the innate and adaptive immune response to primary and subsequent infections as well as reactivation of chronic viral infections. They act during the innate immune response as specialized cells that survey and detect antigens of foreign microorganisms throughout the body thereby inducing their ability to communicate with helper and effector lymphocytes to bridge the innate and adaptive response (Clark etal., 2000; Geissmann et al., 2010). In addition, plasmacytoid dendritic cells (pDC) of lymphoid origin recognize single-stranded RNA and unmethylated $\mathrm{CpG}$ motifs associated with viral infection to help induce an antiviral response within the host (West etal., 2011). Infection of monocytes and DC by both gammaherpesviruses, HHV-8 and Epstein-Barr virus (EBV), has been shown to diminish the subsequent $\mathrm{T}$ cell response (Li et al., 2002; Rappocciolo et al., 2006a; Hensler et al., 2009). However, the manner in which DC infection alters the cellular response associated with HHV-8 infection and its impact on HHV-8 associated disease is minimally understood.

Despite multiple attempts to generate reliable animal models of HHV-8-associated diseases, the overall lack of suitable in vivo models has limited HHV-8 pathogenesis research. A humanizedBLT mouse model has recently been successfully used to establish 
lytic and latent infection in human B cells and macrophages (Wang etal., 2014), and augurs well for future research on HHV-8. Here we focus on the role of DC in the establishment of HHV-8 primary and latent infection predominantly using in vitro models, including the functional state of DC during HHV-8 infection and the current understanding of the factors influencing virus - DC interactions in the context of HHV-8-associated disease.

\section{CELLULAR RECEPTORS FOR HHV-8 INFECTION ATTACHMENT RECEPTORS}

The establishment of HHV-8 infection requires two separate events at the surface of susceptible cells - namely binding to an attachment receptor followed by binding to one or more entry receptors. Prior to the initiation of virus entry, attachment occurs by the direct interactions of viral glycoproteins B (gB) and K8.1 with the attachment receptor heparan sulfate (HS) on the cell surface (Akula et al., 2001a,b; Birkmann et al., 2001; Wang et al., 2001a). This has been supported by evidence that soluble heparin, a molecule similar in structure to HS, blocks HHV-8 attachment to fibroblasts in a dose-dependent manner (Akula et al., 2001b). However, soluble heparin is not sufficient to completely block HHV-8 infection of fibroblasts or endothelial cells (Akula et al., 2001b; Birkmann etal., 2001), suggesting that virus entry is a multi-step process and there may be other attachment factors involved. Yet, the ubiquitous nature of HS expression on host cells may explain the broad range of cellular targets of this virus.

\section{ENTRY RECEPTORS}

Several receptors in the extracellular matrix have been implicated in HHV-8 entry of different human cell types. Dendritic cell-specific ICAM-3-grabbing non-integrin (DC-SIGN) has been revealed as a receptor for HHV-8 infection of MDDC, monocytes, and monocyte-derived macrophages (Rappocciolo et al., 2006a; Kerur et al., 2010), as well as B cells (Rappocciolo et al., 2008). More recently we have shown that $\mathrm{gB}$ of HHV- 8 binds to DCSIGN (Hensler et al., 2014). In addition, our group has shown that HHV-8 infection of MDDC is associated with a decrease in DC-SIGN expression (Rappocciolo et al., 2006a). Integrin $\alpha_{3} \beta_{1}$ has been demonstrated as a cellular receptor for HHV-8 infection on vascular endothelial cells and foreskin fibroblasts (Akula et al., 2002). Most recently, the ephrin receptor tyrosine kinase A2 has been found to serve as a receptor for $\mathrm{HHV}-8$ infection mediated by interactions with the viral glycoprotein $\mathrm{L}$ and $\mathrm{H}$ dimer, specifically on HS-negative cells (Hahn et al., 2012), which had previously been identified as a viral surface complex essential for entry into susceptible host cells (Campadelli-Fiume et al., 2007). Interestingly, this receptor has been shown to be expressed on LC (Munthe et al., 2004), suggesting that these cells could be susceptible to HHV-8 infection.

These reports support that HHV-8 is capable of recognizing multiple receptors on human host cells, and emphasize that our understanding of HHV-8 attachment, entry, and possibly spread throughout the host is still limited. Minimal data exist demonstrating the role of gL and $\mathrm{gH}$ in HHV-8 infection, specifically on HS-positive cells that likely use HS as an initial receptor for attachment. The viral $\mathrm{gB}$ has been demonstrated to bind to both DC-SIGN and the integrin $\alpha_{3} \beta_{1}$ (Akula et al., 2002; Sharma-Walia etal., 2004). It is unclear whether either receptor alone is sufficient for both viral attachment and entry. HHV-8 (like other human herpesviruses) likely utilizes receptor flexibility to expand the range of cell types it infects and adapt to different immunological environments that it encounters in the host.

\section{HHV-8 TRANSMISSION MUCOSAL TRANSMISSION}

The oral cavity is the most common portal of entry and route of transmission for HHV-8 (Pica and Volpi, 2007) leading to inevitable virus exposure to mucosal surfaces of the oropharynx. In fact, HHV-8 DNA can be detected by PCR from intact virions in the majority of saliva samples from seropositive individuals (Koelle et al., 1997; Vieira et al., 1997). Given the strategic positions of LC and SMDC at the mucosal sites, these cells could be the first targets of HHV- 8 infection. The primary role of such $\mathrm{mDC}$ is the detection, uptake, and processing of foreign microbes for antigen presentation to T cells in secondary lymphoid organs, an efficient method of activating the adaptive immune response and establishing immunologic memory against invaders. Based on this function of $\mathrm{mDC}$, they are constantly exposed to and interacting with pathogens and are thereby likely targets of HHV-8 infection. LC are the primary subset of DC found in the epidermal layer of the skin and within the epithelia lining mucosal surfaces (Iwasaki, 2007), both of which are functional physical barriers that serve as the primary defense mechanism against pathogens. Although LC do not express the HHV-8 entry receptor DC-SIGN (Soilleux and Coleman, 2001; Soilleux et al., 2002), they do express the HHV-8 attachment receptor HS on their surface (Yan et al., 2004). LC also express langerin, a type II transmembrane C-type lectin which could potentially be also acting as a receptor for HHV-8 (Valladeau et al., 2000). Interestingly, langerin has been shown to bind HIV-1 and subsequently transport it to the Birbeck granules for degradation, thus forming a protective barrier to HIV-1 dissemination (de Witte et al., 2007). Such studies of LC in HHV-8 infection are hampered by difficulties in obtaining human LC in sufficient quantities and a natural homeostatic state. Alternatively, susceptibility to HHV-8 infection could be assessed using an established in vitro model of deriving LC from $\mathrm{CD}_{4} 4^{+}$hematopoietic cells (Ratzinger et al., 2004). Interestingly, infection of LC plays a role in the pathogenesis of EBV (Walling et al., 2007). Whether LC are targets for HHV-8 infection, and langerin acts as a receptor or protective factor, may open a new avenue toward understanding HHV-8 establishment of latency and reactivation.

In addition to LC, SMDC are found in lamina propria below the epithelial surface of the oral cavity (Cutler and Jotwani, 2006). In vitro and in vivo HHV-8 infection of SMDC has yet to be shown. Nonetheless, unlike LC, SMDC express DC-SIGN (Cutler and Jotwani, 2006) suggesting that they are permissive to HHV-8 infection (Rappocciolo et al., 2006a). In conclusion, due to their physical location and central function in $\mathrm{T}$ cell activation, it would be physiologically relevant for HHV-8 to target mucosal residing DC for replication and transport into the lymphatic system. 
Human herpesvirus 8 transmission through the genital tract is considered less likely due to the lower levels of detectable virus found in semen and vaginal secretions compared to saliva (Edelman, 2005). However, it is still a major route of transmission and of great concern in high-risk endemic communities (Pica and Volpi, 2007). Interestingly, HHV-8 has been detected in tissue of normal non-cancerous prostates from men who have succumbed to AIDS (Montgomery et al., 2006). HHV-8 can also be detected in cervicovaginal secretions of HIV-1/HHV-8 co-infected women (Lisco et al., 2006), and although it is rare, vertical transmission of HHV-8 has been recorded (Brayfield et al., 2003). LC and SMDC are both found within the epithelial lining of the ectocervix and the vagina (Iwasaki, 2007). The function of immune cells in the female reproductive tract is known to be heavily controlled by hormone production, and their phenotype and function is not fully understood (Iwasaki, 2007). Therefore, based on possible differences in receptor expression, the susceptibility of genital tract DC to HHV-8 infection may vary compared to their counterparts in oral mucosa, which could at least in part explain the differential transmission seen between oral and sexual routes.

\section{BLOOD-BORNE TRANSMISSION}

Human herpesvirus 8 can be transmitted through exposure to infectious blood products. Cases of HHV-8 seroconversion associated with blood transfusion, organ transplantation, and intravenous drug use have been reported, however, the latter may be indicative of other high-risk behaviors associated with drug use (Pica and Volpi, 2007). Blood-borne transmission directly exposes immune cells circulating in the vascular system, such as $\mathrm{mDC}$, to the virus much quicker than natural exposure through the oral or genital route. $\mathrm{mDC}$ are sparsely distributed throughout the body (Banchereau and Steinman, 1998), which has made them difficult to study. The development of an in vitro model of deriving MDDC from peripheral blood monocytes with GM-CSF and interleukin 4 (IL-4; Sallusto and Lanzavecchia, 1994) eased the study of this DC subpopulation, as they closely resemble the function of in vivo mDC (Qu etal., 2009; Cheong et al., 2010). The in vitro derived MDDC express DC-SIGN on their surface through which HHV-8 enters and establishes low levels of lytic replication, but display little viral DNA turnover (Rappocciolo et al., 2006a). Differences in primary sites of $\mathrm{HHV}-8$ infection likely influence the host response to infection. Due to a non-robust replication cycle within MDDC and little evidence that LC and SMDC support HHV-8 replication, it is likely the virus also spreads further into the host through cells other than DC.

\section{HHV-8 INFILTRATION OF THE LYMPHATIC SYSTEM TRAFFICKING TO LYMPHOID ORGANS}

How HHV-8 travels to and infects cells within secondary lymphoid tissue is not fully understood. The mucosal immune system, both oral and urogenital, is highly sensitized to the detection of and protection from foreign microbes. However, when an organism breaches this primary line of defense, resident immune cells detect the intrusion and produce pro-inflammatory cytokines. Such soluble molecules increase the migration of maturing LC and SMDC into the mucosal lamina propria (Jotwani and Cutler,
2003) where they engulf foreign antigen, upon which lymphatic homing receptors are up-regulated, such as CCR7, to attract them to CCL19 and CCL21 expressing high endothelial venules (HEVs). This triggers APC migration into lymphatic vessels and trafficking to draining lymph nodes where the foreign antigen is presented to effector T and B cells (Holmgren and Czerkinsky, 2005).

Human herpesvirus 8 likely travels to draining lymphoid organs within DC and monocytes from the primary site of infection, where it can then interact with resident B and T cells. Lytic HHV-8 infection of oral epithelium occurs in vitro (Duus et al., 2004), and has been detected in vivo in monocytes within the cutaneous, highly vascularized lesions of KS patients (Blasig et al., 1997). Macrophages found in tissues and monocytes in peripheral blood travel to draining lymph nodes upon stimulation by foreign microbial antigens, and function in antigen presentation. Macrophages treated with IL-13 express DC-SIGN (Chehimi et al., 2003), resulting in their susceptibility to abortive infection with HHV-8 (Rappocciolo et al., 2006a). Moreover, tissue resident macrophages express DC-SIGN (Soilleux et al., 2002; GranelliPiperno et al., 2005). Therefore, it can be hypothesized that HHV-8 infects the mucosal epithelium and uses proximal DC, and possibly monocytes and macrophages, to penetrate the lymphatic system.

\section{INTERACTION WITH B CELLS}

Immature B cells are abundant in the germinal centers of lymph nodes where they interact with antigen presenting follicular DC (fDC) and follicular T helper cells, and mature during somatic hypermutation and clonal expansion (Beltman et al., 2011). B cells are known to harbor HHV-8 in individuals with KS, PEL, and MCD (Ambroziak et al., 1995; Cesarman et al., 1995; Cesarman and Knowles, 1999). In fact, HHV-8 isolated from PEL-derived cell lines has been used to infect $\mathrm{CD} 19^{+} \mathrm{B}$ cells in vitro (Mesri et al., 1996; Rappocciolo et al., 2008). Extensive evidence indicates that peripheral blood $\mathrm{B}$ cells from healthy individuals support productive lytic HHV-8 infection in vitro when activated with CD40L and IL-4, whereas tonsillar B cells do so without requiring ex vivo activation (Rappocciolo et al., 2008). More recent work in our laboratory shows that HHV-8 targets a range of naïve B cell, IgM memory B cell, and plasma celllike populations both after in vitro infection and circulating in the blood of HIV-1 infected persons with KS (Knowlton et al., 2014).

B cells could also serve as a reservoir of latent $\mathrm{HHV}-8$, as it has been reported that the latency-associated nuclear antigen (LANA1) can be detected in $\operatorname{IgM}^{+} \mathrm{B}$ cells of tonsil origin (Hassman et al., 2011). It is unclear whether each of these B cell subsets is directly infected or derived from infected precursors. Interestingly, $\mathrm{CD}^{+}{ }^{+} \mathrm{T}$ cells are suggested to support latent HHV-8 infection in $\mathrm{B}$ cells by reducing the viral lytic cycle (Myoung and Ganem, 2011). Finally, HHV-8 DNA is detectable in B cells of people with PEL (Cesarman et al., 1995), MCD (Dupin et al., 1999), and KS (Huang et al., 1997; Knowlton et al., 2014). Studies are needed to more directly assess the role of HHV-8 infection of B cells in endothelial cell transformation associated with KS. 
Our most recent data show that HHV-8 infected B cells display a novel polyfunctional cytokine production profile, with an abundance of IL-6, tumor necrosis factor $\alpha$ (TNF $\alpha)$, macrophage inhibitory protein-1 $\alpha$ (MIP- $1 \alpha)$, macrophage inhibitory protein$1 \beta$ (MIP-1b) and IL-8 after in vitro infection and in the blood of HHV-8/HIV-1 co-infected subjects with KS (Knowlton et al., 2014). This systemic, B cell cytokine and chemokine milieu could be important in driving endothelial cell outgrowth in KS, and contribute to the development of HHV-8 associated malignancies. However, it is still unclear whether various $B$ cell lineage subsets are equally susceptible to HHV-8 lytic and latent infection, or if $B$ cell subset precursors are infected and as a result driven into differentiation. Investigation of the natural progression of $\mathrm{HHV}-8$ infection in B cells, as well as DC and monocytes/macrophages, is required to bridge the gap in our knowledge between the APC viral reservoir and transformation of endothelial cells in KS.

\section{INTERACTION WITH T CELLS}

Naïve T cells enter lymph nodes through HEVs where they interact with incoming APC, with both cell types concentrating in paracortical zones where $\mathrm{T}$ cell activation occurs (Liao and Padera, 2013). The killing function of cytotoxic $\mathrm{CD} 8^{+} \mathrm{T}$ lymphocytes (CTLs) in response to intracellular viral antigen presentation is paramount to clearing the body of infected cells. MHC class I restricted $\left(\mathrm{CD}^{+}\right)$responses to $\mathrm{HHV}-8$ protein specific epitopes have been detected (Osman et al., 1999; Wang et al., 2002; Wilkinson et al., 2002). HHV-8 specific T cell responses in individuals are not as pronounced as, for example, EBV (Hislop et al., 2007; Robey et al., 2010), but are nonetheless sufficient to control primary HHV-8 infection and provide life-long protection from HHV-8 cancers in immunocompetent individuals (Wang et al., 2001b).

Follicular DC make up a subset of DC with ontogeny distinct from $\mathrm{mDC}$ and $\mathrm{pDC}$ that reside in secondary lymphoid organs and specialize in antigen presentation (King and Katz, 1990) as well as provide anti-apoptotic stimuli during activation of B cells (Park and Choi, 2005). HHV-8 is not detectable, based on monoclonal antibody staining for ORF73 (LANA-1), in fDC within lymph nodes isolated from KS, PEL, and MCD patients (Dupin et al., 1999). However, a more comprehensive and sensitive analysis of lytic and latent gene expression using an established DNA array of every HHV-8 ORF (Jenner et al., 2001) may be more insightful for detecting HHV-8 infection of not only fDC but other target cells. It is important to further investigate if fDC interactions with $\mathrm{T}$ and $\mathrm{B}$ cells influence $\mathrm{HHV}-8$ infection and pathogenesis.

Previous studies by our group demonstrate that HHV-8 infection of MDDC in vitro reduces their level of endocytosis as well as inhibits their ability to activate virus-specific $\mathrm{CD}^{+} \mathrm{T}$ cells (Rappocciolo et al., 2006a). In addition, Gregory et al. (2012) established latent HHV-8 infection of a monocyte cell line in vitro as a model to study the impact of HHV-8 on monocyte function. Latent viral infection of the monocyte cell line was associated with a dampened inflammatory and adaptive immune response, indicated by a decrease in proinflammatory cytokine production and monocyte co-stimulatory molecule expression associated with $\mathrm{T}$ cell activation. It has also been reported that HHV-8 can enter T lymphocytes from tonsils and result in an abortive infection (Myoung and Ganem, 2011). Finally, LC are known to strongly induce activation of $\mathrm{CD}^{+}$(Furio et al., 2010) and $\mathrm{CD}^{+} \mathrm{T}$ cells (Klechevsky et al., 2008), opening the possibility that HHV-8 directly affects this ability of LC to activate $\mathrm{T}$ cells. In sum, whether virus is interacting with MDDC and monocytes in circulation or tissue, or with LC and SMDC in the mucosa, $\mathrm{T}$ cell responses are likely altered. This must be viewed however, with the fact that HHV-8 infection does not result in high-risk for disease in immunocompetent people.

\section{IN HHV-8-ASSOCIATED DISEASE}

Despite the wide range of permissive and potentially susceptible host cells and substantial immune modulation associated with infection, most HHV-8-associated pathologies only occur when the immune response is compromised by HIV-1 coinfection or another secondary mechanism such as immunosuppression caused by anti-rejection drugs during organ transplantation and by older age. AIDS-associated cancers, including KS and non-Hodgkin's lymphomas such as PEL are strongly influenced by $\mathrm{T}$ cell immunosuppression (Frisch et al., 2001). In addition, KS has been shown to develop more quickly if primary HHV-8 infection occurs after HIV-1 infection (Jacobson etal., 2000). Based on such epidemiological data, substandard $\mathrm{T}$ cell function and consequent ineffective control of virus lytic reactivation are a major basis for susceptibility to HHV-8 disease. This potentially implicates abnormalities in $\mathrm{DC}$ as a basis for such $\mathrm{T}$ cell dysfunction during HHV-8 infection.

\section{KAPOSI'S SARCOMA}

Human herpesvirus 8 was initially isolated from tissue samples of AIDS-associated KS patients and identified as a unique gammaherpesvirus similar to but distinct from EBV (Chang et al., 1994). Today, HHV-8 is associated with all forms of KS irrespective of immunocompromised status. Perhaps what is most puzzling is that the extensive array of lytic and latent gene products encoded by HHV-8 that mimic host immunoregulatory proteins as well as growth factors are insufficient to cause KS (Mesri et al., 2010). We (Knowlton et al., 2012) and others (Rezaee et al., 2006) hypothesize that a specific cytokine and chemokine environment enhances outgrowth of HHV-8 infected, vascular endothelial cells. It is therefore likely that the impact of HHV-8 infection of DC on $\mathrm{T}$ and $\mathrm{B}$ cell cytokine and chemokine production is important in this pathogenic process.

From a historical perspective, DDC were associated with both AIDS-associated and non-AIDS-associated KS lesions prior to the identification of HHV-8 as the etiological agent of KS (Nickoloff and Griffiths, 1989), yet data concerning DDC in AIDS-associated KS are limited and need to be expanded. In addition, multiple cell types associated with the dermal and epidermal layers in KS lesions support their role in productive HHV-8 infection. Thus, HHV-8 DNA has been detected in spindle cells and endothelial cells within and overlaying KS lesions (Nickoloff and Griffiths, 1989; Boshoff etal., 1995; Reed et al., 1998). DC quantity and functional quality are lowered or skewed in classic KS patients. 
These patients present with a lower frequency of MDDC and pDC, as well as an up-regulation of the endocytic receptor CD91 and decrease in expression of the $\mathrm{T}$ cell maturation factor IL12 compared to HHV-8 positive individuals without KS (Della Bella et al., 2006). The likelihood of KS development and time to progression after HHV-8 seroconversion varies based on history of previous infections, HIV-1 co-infection, and behavioral characteristics (Armenian et al., 1993). In addition, highly active antiretroviral therapy (HAART) greatly extends the time to progression to AIDS (Hogg et al., 1999), and is associated with a decrease in HHV-8 replication and KS regression (Gill et al., 2002). Therefore, there may be events interfering with the anti-HHV-8 $\mathrm{T}$ cell response that begin years prior to disease. $\mathrm{T}$ cell responses to HHV-8 antigens and the role of DC in these have yet to be compared longitudinally from infection to KS development, and may reveal important implications of immune suppression and KS. There is a similar limited amount of in vivo data assessing $\mathrm{T}$ cells and DC in PEL and MCD.

\section{PRIMARY EFFUSION LYMPHOMA}

Primary effusion lymphoma is an uncommon B cell lymphoma and comprises $4 \%$ of all HIV-1-related non-Hodgkin's lymphoma cases (Simonelli et al., 2003). The presence of HHV-8 infection of oncogenic cells in HIV-1-related (Cesarman et al., 1995; Carbone et al., 1996b; Otsuki et al., 1996; Gessain etal., 1997) and nonHIV-1-related PEL (Nador et al., 1995; Carbone et al., 1996a; Said et al., 1996) is well established, however, the impact of infection on disease development remains unclear. Genome wide analysis of HHV-8 gene expression in latently infected PEL cell lines has demonstrated that multiple virally encoded products, including ORF71 and 72, v-FLIP, and v-cyclin, are expressed (Jenner et al., 2001), which could influence growth characteristics of the infected and uninfected cells.

As seen in $\mathrm{KS}$, there is evidence that the functional quality and phenotype of DC are irregular in patients that present with PEL. Similarly, DC functional abnormalities have been associated with several cancers including melanoma and chronic lymphocytic leukemia (Enk et al., 1997; Orsini et al., 2003). Cirone et al. (2008) demonstrated a reduction in immature DC (iDC) differentiation from $\mathrm{CD}_{14}{ }^{+}$monocytes, as well as phenotypic differences, in the presence of multiple individual PEL cell lines when co-cultured in vitro, compared to iDC derived in the absence of PEL cell lines. This suggests that in addition to reducing the function of DC, HHV-8 can inhibit the activation and differentiation of monocytes into DCs.

\section{MULTICENTRIC CASTLEMAN'S DISEASE}

Multicentric Castleman's disease is another rare lymphoproliferative disease highly correlated with HIV-1 infection (Oksenhendler et al., 1996) that occurs less commonly in HIV-1 seronegative individuals, the type of cases within which it was initially described (Castleman et al., 1956). Frequent co-presentation of MCD and KS raised questions regarding the relationship between MCD and HHV-8. During the same year HHV-8 was isolated from PEL cases, Soulier et al. (1995) detected HHV-8 in 100\% of HIV-1associated MCD cases and 41\% of HIV-1 negative MCD cases. Interestingly, fDC sarcoma is a rare malignant neoplasm that has been associated with Castleman's disease (Chan et al., 2001; Farah et al., 2005), but not yet MCD specifically. Small percentages of fDC from lymph node and spleen samples of MCD cases have been found to express HHV-8 LANA-1. Interestingly, these same fDC are thought to facilitate the increase of $\mathrm{T}$ cell infiltration into these secondary lymphoid organs (El-Daly et al., 2010). This suggests that fDC serve as functional soldiers in the DC arm of defense.

\section{MULTIPLE MYELOMA}

Briefly, the design and use of DC-based treatment and vaccines targeting multiple myeloma was heavily considered and thought to be promising in the late 1990s. HHV-8 infection was initially found in bone marrow DC of patients with multiple myeloma (Rettig et al., 1997). However, evidence since has concluded that bone marrowderived (Mitterer et al., 1998), peripheral blood mononuclear cell (PBMC)-derived (Cull et al., 1998; Yi et al., 1998), and CD34 positive cell-derived (Mitterer et al., 1998) DC from myeloma patients do not contain HHV-8 sequences. In fact, the absence of HHV-8 in DC of these patients increases the feasibility of an autologous, DC-based immunomodulatory therapy for multiple myeloma. However, such treatments have rarely been successful in clinical trials.

\section{EFFECT OF HHV-8 INFECTION ON DC}

Human herpesvirus 8 encodes many cellular protein homologs, such as vIL-6 (Neipel et al., 1997), vMIP-I and -II (Moore et al., 1996), vIRF-1 (Lin et al., 2001), and vGPCR (Cesarman et al., 1996), that could dysregulate the host immune response and increase survival of latently infected cells (Jenner et al., 2001), thus playing a major role in $\mathrm{HHV}-8$ pathogenesis. DC function is notably altered in KS, PEL, and MCD cases as previously described in this review, and the impact of direct HHV-8 infection of DC (Chan et al., 2001; Della Bella et al., 2006; Cirone et al., 2008) correlates with a dampening of DC functionality. A recent report suggests that one manner by which HHV-8 alters DC function is by blocking autophagy, a type of non-apoptotic programmed cell death, through STAT3 activation and the production of IL-6, IL-10, and IL-23 in MDDC in vitro (Santarelli et al., 2014). In addition, HHV-8 infection of DC precursor monocytes has been directly correlated with an inhibition of maturation into iDC and a decrease in functional stimulation of lymphocytes (Cirone et al., 2007).

A dysfunction in immune stimulation of infected DC is supported by earlier studies revealing two HHV-8 encoded proteins, $\mathrm{K} 3$ and $\mathrm{K} 5$, with essential roles in down-regulating $\mathrm{MHC}$ class I molecules via endocytosis from the surface of infected cells (Coscoy and Ganem, 2000; Ishido et al., 2000). Furthermore, despite sharing a $40 \%$ amino acid homology, structural differences between $\mathrm{K} 3$ and $\mathrm{K} 5$ are responsible for the specificity of the class I subtype targeted by each (Ishido et al., 2000). While K3 strongly down-regulates all four MHC class I types, K5 only targets HLA-A, B, and C, the latter of which is only weakly downregulated (Ishido et al., 2000). Interestingly, it has been suggested that K3 and K5 have the ability to decrease levels of DC-SIGN and DC-SIGNR on the surface of virus-infected HEK293 kidney cells (Lang et al., 2013). HHV-8 encoded LANA1 inhibits MHC class I 
presentation on the surface of HEK293 (Kwun et al., 2011). However, it has yet to be revealed if LANA1 functions in this manner in DC. HHV-8 also produces multiple microRNAs, all of which are encoded within latency-associated genes (Samols et al., 2005), and are detectable in latently infected B cell lines suggesting that they play a role in inducing and/or maintenance of HHV-8 latency (Cai et al., 2005). However, their impact on DC function is not clear and could be studied with RNA silencing technology.

Despite an increased progression to disease following immune suppression, it is puzzling how otherwise healthy individuals remain capable of minimizing $\mathrm{HHV}-8$ pathogenesis even with viral factors directly attempting to inhibit the function of DC and other immune cells. Addressing this enigma requires in depth studies of HHV-8 infection of naturally targeted cells including DC.

\section{FUNCTIONAL DC RESPONSES TO HHV-8 INFECTION}

Despite seemingly extensive attempts by the virus to inhibit DC function and evade the host immune response, reports support that DC can contribute positively to the host's battle against HHV-8 infection, as also described in innate and adaptive responses against EBV (Munz, 2014). Up-regulation of DC-SIGN expression on MDDC and B cells during maturation can be induced by IL-4 and CD40L (Relloso et al., 2002; Rappocciolo et al., 2006b). In contrast, type 1 anti-inflammatory cytokines such as interferon (IFN) and TGF- $\beta$ trigger down regulation of DC-SIGN expression of MDDC (Relloso et al., 2002). Together these data suggest that DC-SIGN is positively regulated in response to extracellular pathogen-based immune responses and negatively regulated in response to intracellular pathogenbased responses such as viral infections. This theoretically should help decrease the number of HHV-8 susceptible cells in the host. We have shown that HHV-8 infected MDDC in vitro display a Th2-skewed cytokine response characterized by a significant increase in IL-6, MIP $1 \alpha$, and MIP1 $\beta$ expression within 72 h postinfection. Furthermore, while IL-12p40 increases, production of IL-12 p70 is significantly lower in infected MDDC compared to controls (Hensler et al., 2009). IL12 p70 production is necessary for the induction of an effective CTL response (Wang et al., 2001b). However, there is also evidence that DC derived from HIV-1 infected patients with KS retain the ability to prime CD ${ }^{+}$ T cells against HHV-8 specific antigens (Stebbing et al., 2003), even though they may lack other functional abilities previously discussed.

Plasmacytoid dendritic cells are a subset of DC comprising less than $1 \%$ of PBMC that focus on recognizing and responding to viral infections via TLR signaling (West et al., 2011) and type 1 IFN production (Liu, 2005). HHV-8 can infect pDC resulting in cell activation and IFN $\alpha$ production as a result of TLR9 induced signaling prior to the production of a viral factor that reduces TLR9 signaling and subsequent IFN $\alpha$ production (West et al., 2011). The receptor by which HHV-8 infects pDC has not been identified. However, pDC precursors express DC-SIGN, indicating they could be susceptible to HHV-8 infection (Soilleux et al., 2002). Alternatively, uninfected DC at sites of infection could recognize and engulf distressed, lytically infected cells, such as apoptotic B cells, macrophages, and endothelial cells (Ueno et al., 2007). All together these sustained DC functions should contribute to minimizing HHV-8 pathogenesis and allowing otherwise healthy individuals to handle this chronic infection over a lifetime.

\section{CONCLUSION}

The natural progression of HHV-8 infection of humans is not fully understood. However, it most commonly begins with entry though a mucosal surface, and likely spreads through the lymphatic system through which it accesses immune cells in mucosal associated lymphoid tissue and the circulatory system. The expression of viral cytokines, vGPCR, and microRNA homologs suggests that this virus goes to a great extent to alter host cellular activities in favor of viral replication, disease, and survival. It is, therefore, an enigma how humans deal with chronic life-long HHV-8 infections with minimal morbidity unless otherwise immunocompromised. It is likely that, as with most chronic viral infections, severe disease is not an endpoint goal of HHV-8 in healthy individuals. The virus likely hinders the pathogen detection and surveillance arm of the immune system sufficiently to remain hidden, possibly within B cells.

Despite a non-robust lytic replication cycle in DC, abortive $\mathrm{HHV}-8$ infection is associated with dysfunctional maturation and a dampened $\mathrm{T}$ helper-1 response and up-regulation of $\mathrm{T}$ helper2 cytokine production, yet such responses are sufficient to limit pathogenesis. Intracellular signaling through virus attachment alone may be enough to induce these effects and eliminate the pressure on the virus to establish lytic replication within DC, particularly if it can reproduce using other cells, such as B cells, macrophages, and endothelial cells without traumatic pathogenesis. This suggests HHV-8 intricately alters the immune response to prolong survival while conserving its surrounding environment, the host.

Human herpesvirus 8 infection of an immunocompromised host increases the likelihood of HHV-8 associated disease development, such as KS. In addition, immune suppression after HHV-8 infection due to, for example, secondary HIV-1 infection or organ transplantation, is also associated with disease development. We theorize, as others have in the past (Osman et al., 1999), that the dampened immune activation and specific HHV- 8 responses controlling chronic HHV-8 infection in healthy persons are not sufficient in a significantly immune compromised environment. The tug-of-war between this virus and the human host appears sophisticated. However, the process has not been fully elucidated, and uncovering the components involved should continue to be of great interest to the fields of cancer biology, virology, immunology, and cell biology.

\section{REFERENCES}

Akula, S. M., Pramod, N. P., Wang, F. Z., and Chandran, B. (2001a). Human herpesvirus 8 envelope-associated glycoprotein B interacts with heparan sulfate-like moieties. Virology 284, 235-249. doi: 10.1006/viro. 2001.0921

Akula, S. M., Wang, F. Z., Vieira, J., and Chandran, B. (2001b). Human herpesvirus 8 interaction with target cells involves heparan sulfate. Virology 282, 245-255. doi: 10.1006/viro.2000.0851

Akula, S. M., Pramod, N. P., Wang, F. Z., and Chandran, B. (2002). Integrin alpha3betal $(\mathrm{CD} 49 \mathrm{c} / 29)$ is a cellular receptor for Kaposi's sarcoma-associated 
herpesvirus (KSHV/HHV-8) entry into the target cells. Cell 108, 407-419. doi: 10.1016/S0092-8674(02)00628-1

Ambroziak, J. A., Blackbourn, D. J., Herndier, B. G., Glogau, R. G., Gullett, J. H., Mcdonald, A. R., etal. (1995). Herpes-like sequences in HIV-infected and uninfected Kaposi's sarcoma patients. Science 268, 582-583. doi: 10.1126/science. 7725108

Armenian, H. K., Hoover, D. R., Rubb, S., Metz, S., Kaslow, R., Visscher, B., et al. (1993). Composite risk score for Kaposi's sarcoma based on a case-control and longitudinal study in the Multicenter AIDS Cohort Study (MACS) population. Am. J. Epidemiol. 138, 256-265.

Banchereau, J., and Steinman, R. M. (1998). Dendritic cells and the control of immunity. Nature 392, 245-252. doi: 10.1038/32588

Beltman, J. B., Allen, C. D., Cyster, J. G., and De Boer, R. J. (2011). B cells within germinal centers migrate preferentially from dark to light zone. Proc. Natl. Acad. Sci. U.S.A. 108, 8755-8760. doi: 10.1073/pnas. 1101554108

Birkmann, A., Mahr, K., Ensser, A., Yaguboglu, S., Titgemeyer, F., Fleckenstein, B., et al. (2001). Cell surface heparan sulfate is a receptor for human herpesvirus 8 and interacts with envelope glycoprotein K8.1. J. Virol. 75, 11583-11593. doi: 10.1128/JVI.75.23.11583-11593.2001

Blasig, C., Zietz, C., Haar, B., Neipel, F., Esser, S., Brockmeyer, N. H., et al. (1997). Monocytes in Kaposi's sarcoma lesions are productively infected by human herpesvirus 8. J. Virol. 71, 7963-7968.

Boshoff, C., Schulz, T. F., Kennedy, M. M., Graham, A. K., Fisher, C., Thomas, A., et al. (1995). Kaposi's sarcoma-associated herpesvirus infects endothelial and spindle cells. Nat. Med. 1, 1274-1278. doi: 10.1038/nm1295-1274

Brayfield, B. P., Phiri, S., Kankasa, C., Muyanga, J., Mantina, H., Kwenda, G., et al. (2003). Postnatal human herpesvirus 8 and human immunodeficiency virus type 1 infection in mothers and infants from Zambia. J. Infect. Dis. 187, 559-568. doi: $10.1086 / 367985$

Cai, X., Lu, S., Zhang, Z., Gonzalez, C. M., Damania, B., and Cullen, B. R. (2005). Kaposi's sarcoma-associated herpesvirus expresses an array of viral microRNAs in latently infected cells. Proc. Natl. Acad. Sci. U.S.A. 102, 5570-5575. doi: 10.1073/pnas.0408192102

Campadelli-Fiume, G., Amasio, M., Avitabile, E., Cerretani, A., Forghieri, C., Gianni, T., et al. (2007). The multipartite system that mediates entry of herpes simplex virus into the cell. Rev. Med. Virol. 17, 313-326. doi: 10.1002/rmv.546

Carbone, A., Gloghini, A., Vaccher, E., Zagonel, V., Pastore, C., Dalla Palma, P., et al. (1996a). Kaposi's sarcoma-associated herpesvirus DNA sequences in AIDSrelated and AIDS-unrelated lymphomatous effusions. Br. J. Haematol. 94, 533543. doi: 10.1046/j.1365-2141.1996.d01-1826.x

Carbone, A., Tirelli, U., Gloghini, A., Pastore, C., Vaccher, E., and Gaidano, G. (1996b). Herpesvirus-like DNA sequences selectively cluster with body cavity-based lymphomas throughout the spectrum of AIDS-related lymphomatous effusions. Eur. J. Cancer 32A, 555-556. doi: 10.1016/0959-8049(95) 00594-3

Castleman, B., Iverson, L., and Menendez, V. P. (1956). Localized mediastinal lymphnode hyperplasia resembling thymoma. Cancer 9, 822-830. doi: 10.1002/1097-0142(195607/08)9:4<822::AID-CNCR2820090430>3.0.CO;2-4

Cesarman, E., Chang, Y., Moore, P. S., Said, J. W., and Knowles, D. M. (1995). Kaposi's sarcoma-associated herpesvirus-like DNA sequences in AIDSrelated body-cavity-based lymphomas. N. Engl. J. Med. 332, 1186-1191. doi: 10.1056/NEJM199505043321802

Cesarman, E., and Knowles, D. M. (1999). The role of Kaposi's sarcoma-associated herpesvirus (KSHV/HHV-8) in lymphoproliferative diseases. Semin. Cancer Biol. 9, 165-174. doi: 10.1006/scbi.1998.0118

Cesarman, E., Nador, R. G., Bai, F., Bohenzky, R. A., Russo, J. J., Moore, P. S., et al. (1996). Kaposi's sarcoma-associated herpesvirus contains $G$ protein-coupled receptor and cyclin D homologs which are expressed in Kaposi's sarcoma and malignant lymphoma. J. Virol. 70, 8218-8223.

Chan, A. C., Chan, K. W., Chan, J. K., Au, W. Y., Ho, W. K., and Ng, W. M. (2001). Development of follicular dendritic cell sarcoma in hyaline-vascular Castleman's disease of the nasopharynx: tracing its evolution by sequential biopsies. Histopathology 38, 510-518. doi: 10.1046/j.1365-2559.2001.01134.x

Chang, Y., Cesarman, E., Pessin, M. S., Lee, F., Culpepper, J., Knowles, D. M., et al. (1994). Identification of herpesvirus-like DNA sequences in AIDS-associated Kaposi's sarcoma. Science 266, 1865-1869. doi: 10.1126/science.7997879

Chehimi, J., Luo, Q., Azzoni, L., Shawver, L., Ngoubilly, N., June, R., et al. (2003). HIV-1 transmission and cytokine-induced expression of DC-SIGN in human monocyte-derived macrophages. J. Leukoc. Biol. 74, 757-763. doi: 10.1189/jlb.0503231

Cheong, C., Matos, I., Choi, J. H., Dandamudi, D. B., Shrestha, E., Longhi, M. P., et al. (2010). Microbial stimulation fully differentiates monocytes to DCSIGN/CD209(+) dendritic cells for immune T cell areas. Cell 143, 416-429. doi: 10.1016/j.cell.2010.09.039

Cirone, M., Lucania, G., Aleandri, S., Borgia, G., Trivedi, P., Cuomo, L., et al. (2008). Suppression of dendritic cell differentiation through cytokines released by Primary Effusion Lymphoma cells. Immunol. Lett. 120, 37-41. doi: 10.1016/j.imlet.2008.06.011

Cirone, M., Lucania, G., Bergamo, P., Trivedi, P., Frati, L., and Faggioni, A. (2007). Human herpesvirus 8 (HHV-8) inhibits monocyte differentiation into dendritic cells and impairs their immunostimulatory activity. Immunol. Lett. 113, 40-46. doi: 10.1016/j.imlet.2007.07.013

Clark, G. J., Angel, N., Kato, M., Lopez, J. A., Macdonald, K., Vuckovic, S., et al. (2000). The role of dendritic cells in the innate immune system. Microbes Infect. 2, 257-272. doi: 10.1016/S1286-4579(00)00302-6

Coscoy, L., and Ganem, D. (2000). Kaposi's sarcoma-associated herpesvirus encodes two proteins that block cell surface display of MHC class I chains by enhancing their endocytosis. Proc. Natl. Acad. Sci. U.S.A. 97, 8051-8056. doi: 10.1073/pnas.140129797

Cull, G. M., Timms, J. M., Haynes, A. P., Russell, N. H., Irving, W. L., Ball, J. K., et al. (1998). Dendritic cells cultured from mononuclear cells and CD34 cells in myeloma do not harbour human herpesvirus 8. Br. J. Haematol. 100, 793-796. doi: 10.1046/j.1365-2141.1998.00671.x

Cutler, C. W., and Jotwani, R. (2006). Dendritic cells at the oral mucosal interface. J. Dent. Res. 85, 678-689. doi: 10.1177/154405910608500801

Della Bella, S., Nicola, S., Brambilla, L., Riva, A., Ferrucci, S., Presicce, P., et al. (2006). Quantitative and functional defects of dendritic cells in classic Kaposi's sarcoma. Clin. Immunol. 119, 317-329. doi: 10.1016/j.clim.2006.01.011

de Witte, L., Nabatov, A., Pion, M., Fluitsma, D., De Jong, M. A., De Gruijl, T., et al. (2007). Langerin is a natural barrier to HIV-1 transmission by Langerhans cells. Nat. Med. 13, 367-371. doi: 10.1038/nm1541

Dupin, N., Fisher, C., Kellam, P., Ariad, S., Tulliez, M., Franck, N., et al. (1999). Distribution of human herpesvirus-8 latently infected cells in Kaposi's sarcoma, multicentric Castleman's disease, and primary effusion lymphoma. Proc. Natl. Acad. Sci. U.S.A. 96, 4546-4551. doi: 10.1073/pnas.96.8.4546

Duus, K. M., Lentchitsky, V., Wagenaar, T., Grose, C., and Webster-Cyriaque, J. (2004). Wild-type Kaposi's sarcoma-associated herpesvirus isolated from the oropharynx of immune-competent individuals has tropism for cultured oral epithelial cells. J. Virol. 78, 4074-4084. doi: 10.1128/JVI.78.8.40744084.2004

Edelman, D. C. (2005). Human herpesvirus 8 - a novel human pathogen. Virol. J. 2:78. doi: 10.1186/1743-422X-2-78

El-Daly, H., Bower, M., and Naresh, K. N. (2010). Follicular dendritic cells in multicentric Castleman disease present human herpes virus type 8 (HHV8)latent nuclear antigen 1 (LANA1) in a proportion of cases and is associated with an enhanced T-cell response. Eur. J. Haematol. 84, 133-136. doi: 10.1111/j.16000609.2009.01358.x

Enk, A. H., Jonuleit, H., Saloga, J., and Knop, J. (1997). Dendritic cells as mediators of tumor-induced tolerance in metastatic melanoma. Int. J. Cancer 73, 309-316. doi: 10.1002/(SICI) 1097-0215(19971104)73:3<309::AID-IJC1>3.0.CO;2-3

Farah, C. S., Mohamad Zaini, Z., Savage, N. W., and Norris, D. (2005). Follicular dendritic cell sarcoma associated with Castlemans's disease presenting in the oral cavity. Oral Oncol. Extra 42:4.

Frisch, M., Biggar, R. J., Engels, E. A., Goedert, J. J., and AIDS-Cancer Match Registry Study Group. (2001). Association of cancer with AIDS-related immunosuppression in adults. JAMA 285, 1736-1745. doi: 10.1001/jama.285.13.1736

Furio, L., Briotet, I., Journeaux, A., Billard, H., and Peguet-Navarro, J. (2010). Human langerhans cells are more efficient than CD14(-)CD1c(+) dermal dendritic cells at priming naive CD4(+) T cells. J. Invest. Dermatol. 130, 1345-1354. doi: 10.1038/jid.2009.424

Geissmann, F., Manz, M. G., Jung, S., Sieweke, M. H., Merad, M., and Ley, K. (2010). Development of monocytes, macrophages, and dendritic cells. Science 327, 656-661. doi: 10.1126/science.1178331

Gessain, A., Briere, J., Angelin-Duclos, C., Valensi, F., Beral, H. M., Davi, F., et al. (1997). Human herpes virus 8 (Kaposi's sarcoma herpes virus) and malignant lymphoproliferations in France: a molecular study of 250 cases including two 
AIDS-associated body cavity based lymphomas. Leukemia 11, 266-272. doi: 10.1038/sj.leu.2400549

Gill, J., Bourboulia, D., Wilkinson, J., Hayes, P., Cope, A., Marcelin, A. G., etal. (2002). Prospective study of the effects of antiretroviral therapy on Kaposi sarcoma-associated herpesvirus infection in patients with and without Kaposi sarcoma. J. Acquir. Immune Defic. Syndr. 31, 384-390. doi: 10.1097/00126334-200212010-00003

Granelli-Piperno, A., Pritsker, A., Pack, M., Shimeliovich, I., Arrighi, J. F., Park, C. G., et al. (2005). Dendritic cell-specific intercellular adhesion molecule 3grabbing nonintegrin/CD209 is abundant on macrophages in the normal human lymph node and is not required for dendritic cell stimulation of the mixed leukocyte reaction. J. Immunol. 175, 4265-4273. doi: 10.4049/jimmunol.175. 7.4265

Gregory, S. M., Wang, L., West, J. A., Dittmer, D. P., and Damania, B. (2012). Latent Kaposi's sarcoma-associated herpesvirus infection of monocytes downregulates expression of adaptive immune response costimulatory receptors and proinflammatory cytokines. J. Virol. 86, 3916-3923. doi: 10.1128/JVI. 06437-11

Hahn, A. S., Kaufmann, J. K., Wies, E., Naschberger, E., Panteleev-Ivlev, J., Schmidt K., etal. (2012). The ephrin receptor tyrosine kinase A2 is a cellular receptor for Kaposi's sarcoma-associated herpesvirus. Nat. Med. 18, 961-966. doi: $10.1038 / \mathrm{nm} .2805$

Hassman, L. M., Ellison, T. J., and Kedes, D. H. (2011). KSHV infects a subset of human tonsillar B cells, driving proliferation and plasmablast differentiation. J. Clin. Invest. 121, 752-768. doi: 10.1172/JCI44185

Hensler, H. R., Rappocciolo, G., Rinaldo, C. R., and Jenkins, F. J. (2009). Cytokine production by human herpesvirus 8 -infected dendritic cells. J. Gen. Virol. 90, 79-83. doi: 10.1099/vir.0.006239-0

Hensler, H. R., Tomaszewski, M. J., Rappocciolo, G., Rinaldo, C. R., and Jenkins, F. J. (2014). Human herpesvirus 8 glycoprotein B binds the entry receptor DC-SIGN Virus Res. 190C, 97-103. doi: 10.1016/j.virusres.2014.07.003

Hislop, A. D., Taylor, G. S., Sauce, D., and Rickinson, A. B. (2007). Cellular responses to viral infection in humans: lessons from Epstein-Barr virus. Annu. Rev. Immunol. 25, 587-617. doi: 10.1146/annurev.immunol.25.022106.141553

Hogg, R. S., Yip, B., Kully, C., Craib, K. J., O’Shaughnessy, M. V., Schechter, M. T., et al. (1999). Improved survival among HIV-infected patients after initiation of triple-drug antiretroviral regimens. CMAJ 160, 659-665.

Holmgren, J., and Czerkinsky, C. (2005). Mucosal immunity and vaccines. Nat. Med. 11, S45-S53. doi: 10.1038/nm1213

Huang, Y. Q., Li, J. J., Poiesz, B. J., Kaplan, M. H., and Friedman-Kien, A. E. (1997). Detection of the herpesvirus-like DNA sequences in matched specimens of semen and blood from patients with AIDS-related Kaposi's sarcoma by polymerase chain reaction in situ hybridization. Am. J. Pathol. 150, 147-153.

Ishido, S., Wang, C., Lee, B. S., Cohen, G. B., and Jung, J. U. (2000). Downregulation of major histocompatibility complex class I molecules by Kaposi's sarcoma-associated herpesvirus K3 and K5 proteins. J. Virol. 74, 5300-5309. doi: 10.1128/JVI.74.11.5300-5309.2000

Iwasaki, A. (2007). Mucosal dendritic cells. Annu. Rev. Immunol. 25, 381-418. doi: 10.1146/annurev.immunol.25.022106.141634

Jacobson, L. P., Jenkins, F. J., Springer, G., Munoz, A., Shah, K. V., Phair, J., et al. (2000). Interaction of human immunodeficiency virus type 1 and human herpesvirus type 8 infections on the incidence of Kaposi's sarcoma. J. Infect. Dis. 181, 1940-1949. doi: 10.1086/315503

Jenner, R. G., Alba, M. M., Boshoff, C., and Kellam, P. (2001). Kaposi's sarcomaassociated herpesvirus latent and lytic gene expression as revealed by DNA arrays. J. Virol. 75, 891-902. doi: 10.1128/JVI.75.2.891-902.2001

Jotwani, R., and Cutler, C. W. (2003). Multiple dendritic cell (DC) subpopulations in human gingiva and association of mature DCs with CD4+ T-cells in situ. J. Dent. Res. 82, 736-741. doi: 10.1177/154405910308200915

Kerur, N., Veettil, M. V., Sharma-Walia, N., Sadagopan, S., Bottero, V., Paul, A. G., et al. (2010). Characterization of entry and infection of monocytic THP-1 cells by Kaposi's sarcoma associated herpesvirus (KSHV): role of heparan sulfate, DC-SIGN, integrins and signaling. Virology 406, 103-116. doi: 10.1016/j.virol.2010.07.012

King, P. D., and Katz, D. R. (1990). Mechanisms of dendritic cell function. Immunol. Today 11, 206-211. doi: 10.1016/0167-5699(90)90084-M

Klechevsky, E., Morita, R., Liu, M., Cao, Y., Coquery, S., ThompsonSnipes, L., et al. (2008). Functional specializations of human epidermal
Langerhans cells and CD14+ dermal dendritic cells. Immunity 29, 497-510. doi: 10.1016/j.immuni.2008.07.013

Knowlton, E. R., Lepone, L. M., Li, J., Rappocciolo, G., Jenkins, F. J., and Rinaldo, C. R. (2012). Professional antigen presenting cells in human herpesvirus 8 infection. Front. Immunol. 3:427. doi: 10.3389/fimmu.2012.00427

Knowlton, E. R., Rappocciolo, G., Piazza, P., Lepone, L. M., Nadgir, S. V., Bullotta, A., et al. (2014). Human herpesvirus 8 induces polyfunctional B lymphocytes that drive Kaposi's sarcoma. mBio 5, e01277-e01214.

Koelle, D. M., Huang, M. L., Chandran, B., Vieira, J., Piepkorn, M., and Corey, L. (1997). Frequent detection of Kaposi's sarcoma-associated herpesvirus (human herpesvirus 8) DNA in saliva of human immunodeficiency virus-infected men: clinical and immunologic correlates. J. Infect. Dis. 176, 94-102. doi: 10.1086/514045

Kwun, H. J., Da Silva, S. R., Qin, H., Ferris, R. L., Tan, R., Chang, Y., et al. (2011). The central repeat domain 1 of Kaposi's sarcoma-associated herpesvirus (KSHV) latency associated-nuclear antigen 1 (LANA1) prevents cis MHC class I peptide presentation. Virology 412, 357-365. doi: 10.1016/j.virol.2011.01.026

Lang, S. M., Bynoe, M. O., Karki, R., Tartell, M. A., and Means, R. E. (2013). Kaposi's sarcoma-associated herpesvirus K3 and K5 proteins down regulate both DC-SIGN and DC-SIGNR. PLoS ONE 8:e58056. doi: 10.1371/journal.pone. 0058056

Liao, S., and Padera, T. P. (2013). Lymphatic function and immune regulation in health and disease. Lymphat. Res. Biol. 11, 136-143. doi: 10.1089/lrb.2013.0012

Li, L., Liu, D., Hutt-Fletcher, L., Morgan, A., Masucci, M. G., and Levitsky, V. (2002). Epstein-Barr virus inhibits the development of dendritic cells by promoting apoptosis of their monocyte precursors in the presence of granulocyte macrophage-colony-stimulating factor and interleukin-4. Blood 99, 3725-3734. doi: 10.1182/blood.V99.10.3725

Lin, R., Genin, P., Mamane, Y., Sgarbanti, M., Battistini, A., Harrington, W. J., et al. (2001). HHV-8 encoded vIRF-1 represses the interferon antiviral response by blocking IRF-3 recruitment of the CBP/p300 coactivators. Oncogene 20, 800-811. doi: 10.1038/sj.onc. 1204163

Lisco, A., Barbierato, M., Fiore, J. R., Gasperini, P., Favia, A., Volpe, A., et al. (2006). Pregnancy and human herpesvirus 8 reactivation in human immunodeficiency virus type 1-infected women. J. Clin. Microbiol. 44, 3863-3871. doi: 10.1128/JCM.00791-06

Liu, Y. J. (2005). IPC: professional type 1 interferon-producing cells and plasmacytoid dendritic cell precursors. Annu. Rev. Immunol. 23, 275-306. doi: 10.1146/annurev.immunol.23.021704.115633

Mesri, E. A., Cesarman, E., Arvanitakis, L., Rafii, S., Moore, M. A., Posnett, D. N., et al. (1996). Human herpesvirus-8/Kaposi's sarcoma-associated herpesvirus is a new transmissible virus that infects B cells. J. Exp. Med. 183, 2385-2390. doi: 10.1084/jem.183.5.2385

Mesri, E. A., Cesarman, E., and Boshoff, C. (2010). Kaposi's sarcoma and its associated herpesvirus. Nat. Rev. Cancer 10, 707-719. doi: 10.1038/nrc2888

Mitterer, M., Mair, W., Gatti, D., Sheldon, J., Vachula, M., Coser, P., et al. (1998). Dendritic cells derived from bone marrow and CD34+ selected blood progenitor cells of myeloma patients, cultured in serum-free media, do not contain the Kaposi sarcoma herpesvirus genome. Br. J. Haematol. 102, 1338-1340. doi: 10.1046/j.1365-2141.1998.00894.x

Montgomery, J. D., Jacobson, L. P., Dhir, R., and Jenkins, F. J. (2006). Detection of human herpesvirus 8 (HHV-8) in normal prostates. Prostate 66, 1302-1310. doi: 10.1002/pros.20459

Moore, P. S., Boshoff, C., Weiss, R. A., and Chang, Y. (1996). Molecular mimicry of human cytokine and cytokine response pathway genes by KSHV. Science 274, 1739-1744. doi: 10.1126/science.274.5293.1739

Munthe, E., Finne, E. F., and Aasheim, H. C. (2004). Expression and functional effects of Eph receptor tyrosine kinase A family members on Langerhans like dendritic cells. BMC Immunol. 5:9. doi: 10.1186/1471-2172-5-9

Munz, C. (2014). Dendritic cells during Epstein Barr virus infection. Front. Microbiol. 5:308. doi: 10.3389/fmicb.2014.00308

Myoung, J., and Ganem, D. (2011). Active lytic infection of human primary tonsillar B cells by KSHV and its noncytolytic control by activated CD4+ T cells. J. Clin. Invest. 121, 1130-1140. doi: 10.1172/JCI43755

Nador, R. G., Cesarman, E., Chadburn, A., Dawson, D. B., Ansari, M. Q., Sald, J., et al. (1996). Primary effusion lymphoma: a distinct clinicopathologic entity associated with the Kaposi's sarcoma-associated herpes virus. Blood 88, 645-656. 
Nador, R. G., Cesarman, E., Knowles, D. M., and Said, J. W. (1995). Herpes-like DNA sequences in a body-cavity-based lymphoma in an HIV-negative patient. N. Engl. J. Med. 333:943. doi: 10.1056/NEJM199510053331417

Neipel, F., Albrecht, J. C., Ensser, A., Huang, Y. Q., Li, J. J., Friedman-Kien, A. E., et al. (1997). Human herpesvirus 8 encodes a homolog of interleukin-6. J. Virol. 71, 839-842.

Nickoloff, B. J., and Griffiths, C. E. (1989). The spindle-shaped cells in cutaneous Kaposi's sarcoma. Histologic simulators include factor XIIIa dermal dendrocytes. Am. J. Pathol. 135, 793-800.

Oksenhendler, E., Duarte, M., Soulier, J., Cacoub, P., Welker, Y., Cadranel, J., et al. (1996). Multicentric Castleman's disease in HIV infection: a clinical and pathological study of 20 patients. AIDS 10, 61-67. doi: 10.1097/00002030199601000-00009

Orsini, E., Guarini, A., Chiaretti, S., Mauro, F. R., and Foa, R. (2003). The circulating dendritic cell compartment in patients with chronic lymphocytic leukemia is severely defective and unable to stimulate an effective T-cell response. Cancer Res. 63, 4497-4506.

Osman, M., Kubo, T., Gill, J., Neipel, F., Becker, M., Smith, G., et al. (1999). Identification of human herpesvirus 8-specific cytotoxic T-cell responses. J. Virol. $73,6136-6140$

Otsuki, T., Kumar, S., Ensoli, B., Kingma, D. W., Yano, T., Stetler-Stevenson, M. et al. (1996). Detection of HHV-8/KSHV DNA sequences in AIDS-associated extranodal lymphoid malignancies. Leukemia 10, 1358-1362.

Park, C. S., and Choi, Y. S. (2005). How do follicular dendritic cells interact intimately with B cells in the germinal centre? Immunology 114, 2-10. doi: 10.1111/j.13652567.2004.02075.x

Pica, F., and Volpi, A. (2007). Transmission of human herpesvirus 8: an update. Curr. Opin. Infect. Dis. 20, 152-156. doi: 10.1097/QCO.0b013e3280143919

Qu, C., Nguyen, V. A., Merad, M., and Randolph, G. J. (2009). MHC class I/peptide transfer between dendritic cells overcomes poor cross-presentation by monocyte-derived APCs that engulf dying cells. J. Immunol. 182, 3650-3659. doi: 10.4049/jimmunol.0801532

Rappocciolo, G., Hensler, H. R., Jais, M., Reinhart, T. A., Pegu, A., Jenkins, F. J., et al. (2008). Human herpesvirus 8 infects and replicates in primary cultures of activated B lymphocytes through DC-SIGN. J. Virol. 82, 4793-4806. doi 10.1128/JVI.01587-07

Rappocciolo, G., Jenkins, F. J., Hensler, H. R., Piazza, P., Jais, M., Borowski, L., et al. (2006a). DC-SIGN is a receptor for human herpesvirus 8 on dendritic cells and macrophages. J. Immunol. 176, 1741-1749. doi: 10.4049/jimmunol.176. 3.1741

Rappocciolo, G., Piazza, P., Fuller, C. L., Reinhart, T. A., Watkins, S. C., Rowe, D. T., et al. (2006b). DC-SIGN on B lymphocytes is required for transmission of HIV-1 to T lymphocytes. PLoS Pathog. 2:e70. doi: 10.1371/journal.ppat.0020070

Ratzinger, G., Baggers, J., De Cos, M. A., Yuan, J., Dao, T., Reagan, J. L., et al. (2004). Mature human Langerhans cells derived from CD34+ hematopoietic progenitors stimulate greater cytolytic T lymphocyte activity in the absence of bioactive IL12 p70, by either single peptide presentation or cross-priming, than do dermalinterstitial or monocyte-derived dendritic cells. J. Immunol. 173, 2780-2791. doi 10.4049/jimmunol.173.4.2780

Reed, J. A., Nador, R. G., Spaulding, D., Tani, Y., Cesarman, E., and Knowles, D. M. (1998). Demonstration of Kaposi's sarcoma-associated herpes virus cyclin D homolog in cutaneous Kaposi's sarcoma by colorimetric in situ hybridization using a catalyzed signal amplification system. Blood 91, 3825-3832.

Relloso, M., Puig-Kroger, A., Pello, O. M., Rodriguez-Fernandez, J. L., De La Rosa, G., Longo, N., et al. (2002). DC-SIGN (CD209) expression is IL-4 dependent and is negatively regulated by IFN, TGF-beta, and anti-inflammatory agents. J. Immunol. 168, 2634-2643. doi: 10.4049/jimmunol.168.6.2634

Rettig, M. B., Ma, H. J., Vescio, R. A., Pold, M., Schiller, G., Belson, D., et al. (1997). Kaposi's sarcoma-associated herpesvirus infection of bone marrow dendritic cells from multiple myeloma patients. Science 276, 1851-1854. doi: 10.1126/science.276.5320.1851

Rezaee, S. A., Cunningham, C., Davison, A. J., and Blackbourn, D. J. (2006). Kaposi's sarcoma-associated herpesvirus immune modulation: an overview. J. Gen. Virol 87, 1781-1804. doi: 10.1099/vir.0.81919-0

Robey, R. C., Mletzko, S., and Gotch, F. M. (2010). The T-cell immune response against Kaposi's sarcoma-associated herpesvirus. Adv. Virol. 2010:340356. doi: $10.1155 / 2010 / 340356$
Said, J. W., Tasaka, T., Takeuchi, S., Asou, H., De Vos, S., Cesarman, E., et al. (1996) Primary effusion lymphoma in women: report of two cases of Kaposi's sarcoma herpes virus-associated effusion-based lymphoma in human immunodeficiency virus-negative women. Blood 88, 3124-3128.

Sallusto, F., and Lanzavecchia, A. (1994). Efficient presentation of soluble antigen by cultured human dendritic cells is maintained by granulocyte/macrophage colonystimulating factor plus interleukin 4 and downregulated by tumor necrosis factor alpha. J. Exp. Med. 179, 1109-1118. doi: 10.1084/jem.179.4.1109

Samols, M. A., Hu, J., Skalsky, R. L., and Renne, R. (2005). Cloning and identification of a microRNA cluster within the latency-associated region of Kaposi's sarcoma-associated herpesvirus. J. Virol. 79, 9301-9305. doi: 10.1128/JVI.79.14.9301-9305.2005

Santarelli, R., Gonnella, R., Di Giovenale, G., Cuomo, L., Capobianchi, A., Granato, M., et al. (2014). STAT3 activation by KSHV correlates with IL-10, IL-6, and IL-23 release and an autophagic block in dendritic cells. Sci. Rep. 4:4241. doi: 10.1038 /srep04241

Sharma-Walia, N., Naranatt, P. P., Krishnan, H. H., Zeng, L., and Chandran, B. (2004). Kaposi's sarcoma-associated herpesvirus/human herpesvirus 8 envelope glycoprotein $\mathrm{gB}$ induces the integrin-dependent focal adhesion kinase-Src-phosphatidylinositol 3-kinase-rho GTPase signal pathways and cytoskeletal rearrangements. J. Virol. 78, 4207-4223. doi: 10.1128/JVI.78.8.42074223.2004

Simonelli, C., Spina, M., Cinelli, R., Talamini, R., Tedeschi, R., Gloghini, A., et al. (2003). Clinical features and outcome of primary effusion lymphoma in HIVinfected patients: a single-institution study. J. Clin. Oncol. 21, 3948-3954. doi: 10.1200/JCO.2003.06.013

Soilleux, E. J., and Coleman, N. (2001). Langerhans cells and the cells of Langerhans cell histiocytosis do not express DC-SIGN. Blood 98, 1987-1988. doi: 10.1182/blood.V98.6.1987

Soilleux, E. J., Morris, L. S., Leslie, G., Chehimi, J., Luo, Q., Levroney, E., et al. (2002). Constitutive and induced expression of DC-SIGN on dendritic cell and macrophage subpopulations in situ and in vitro. J. Leukoc. Biol. 71, 445-457.

Soulier, J., Grollet, L., Oksenhendler, E., Cacoub, P., Cazals-Hatem, D., Babinet, P., et al. (1995). Kaposi's sarcoma-associated herpesvirus-like DNA sequences in multicentric Castleman's disease. Blood 86, 1276-1280.

Stebbing, J., Gazzard, B., Portsmouth, S., Gotch, F., Kim, L., Bower, M., et al. (2003). Disease-associated dendritic cells respond to disease-specific antigens through the common heat shock protein receptor. Blood 102, 1806-1814. doi: 10.1182/blood-2003-03-0891

Ueno, H., Klechevsky, E., Morita, R., Aspord, C., Cao, T., Matsui, T., et al. (2007). Dendritic cell subsets in health and disease. Immunol. Rev. 219, 118-142. doi: 10.1111/j.1600-065X.2007.00551.x

Valladeau, J., Ravel, O., Dezutter-Dambuyant, C., Moore, K., Kleijmeer, M., Liu, Y., et al. (2000). Langerin, a novel C-type lectin specific to Langerhans cells, is an endocytic receptor that induces the formation of Birbeck granules. Immunity 12, 71-81. doi: 10.1016/S1074-7613(00)80160-0

Vieira, J., Huang, M. L., Koelle, D. M., and Corey, L. (1997). Transmissible Kaposi's sarcoma-associated herpesvirus (human herpesvirus 8) in saliva of men with a history of Kaposi's sarcoma. J. Virol. 71, 7083-7087.

Walling, D. M., Ray, A. J., Nichols, J. E., Flaitz, C. M., and Nichols, C. M. (2007). Epstein-Barr virus infection of Langerhans cell precursors as a mechanism of oral epithelial entry, persistence, and reactivation. J. Virol. 81, 7249-7268. doi: 10.1128/JVI.02754-06

Wang, F. Z., Akula, S. M., Pramod, N. P., Zeng, L., and Chandran, B. (2001a). Human herpesvirus 8 envelope glycoprotein K8.1A interaction with the target cells involves heparan sulfate. J. Virol. 75, 7517-7527. doi: 10.1128/JVI.75.16.75177527.2001

Wang, Q. J., Jenkins, F. J., Jacobson, L. P., Kingsley, L. A., Day, R. D., Zhang, Z. W., et al. (2001b). Primary human herpesvirus 8 infection generates a broadly specific CD8(+) T-cell response to viral lytic cycle proteins. Blood 97, 2366-2373. doi: 10.1182/blood.V97.8.2366

Wang, L. X., Kang, G., Kumar, P., Lu, W., Li, Y., Zhou, Y., et al. (2014). HumanizedBLT mouse model of Kaposi's sarcoma-associated herpesvirus infection. Proc. Natl. Acad. Sci. U.S.A. 111, 3146-3151. doi: 10.1073/pnas.1318175111

Wang, Q. J., Huang, X. L., Rappocciolo, G., Jenkins, F. J., Hildebrand, W. H., Fan, Z., et al. (2002). Identification of an HLA A*0201-restricted CD8(+) T-cell epitope for the glycoprotein B homolog of human herpesvirus 8. Blood 99, 3360-3366. doi: 10.1182/blood.V99.9.3360 
West, J. A., Gregory, S. M., Sivaraman, V., Su, L., and Damania, B. (2011). Activation of plasmacytoid dendritic cells by Kaposi's sarcoma-associated herpesvirus. J. Virol. 85, 895-904. doi: 10.1128/JVI.01007-10

Wilkinson, J., Cope, A., Gill, J., Bourboulia, D., Hayes, P., Imami, N., et al. (2002). Identification of Kaposi's sarcoma-associated herpesvirus (KSHV)-specific cytotoxic T-lymphocyte epitopes and evaluation of reconstitution of KSHVspecific responses in human immunodeficiency virus type 1-Infected patient receiving highly active antiretroviral therapy. J. Virol. 76, 2634-2640. doi: 10.1128/JVI.76.6.2634-2640.2002

Yan, M., Peng, J., Jabbar, I. A., Liu, X., Filgueira, L., Frazer, I. H., et al. (2004) Despite differences between dendritic cells and Langerhans cells in the mechanism of papillomavirus-like particle antigen uptake, both cells cross-prime $\mathrm{T}$ cells. Virology 324, 297-310. doi: 10.1016/j.virol.2004.03.045

Yi, Q., Ekman, M., Anton, D., Bergenbrant, S., Osterborg, A., Georgii-Hemming, P., et al. (1998). Blood dendritic cells from myeloma patients are not infected with Kaposi's sarcoma-associated herpesvirus (KSHV/HHV-8). Blood 92, 402-404.
Conflict of Interest Statement: The authors declare that the research was conducted in the absence of any commercial or financial relationships that could be construed as a potential conflict of interest.

Received: 02 July 2014; paper pending published: 01 August 2014; accepted: 11 August 2014; published online: 28 August 2014.

Citation: Campbell DM, Rappocciolo G, Jenkins FJ and Rinaldo CR (2014) Dendritic cells: key players in human herpesvirus 8 infection and pathogenesis. Front. Microbiol. 5:452. doi: 10.3389/fmicb.2014.00452

This article was submitted to Virology, a section of the journal Frontiers in Microbiology. Copyright (c) 2014 Campbell, Rappocciolo, Jenkins and Rinaldo. This is an openaccess article distributed under the terms of the Creative Commons Attribution License (CC BY). The use, distribution or reproduction in other forums is permitted, provided the original author(s) or licensor are credited and that the original publication in this journal is cited, in accordance with accepted academic practice. No use, distribution or reproduction is permitted which does not comply with these terms. 